\title{
Erratum to: Special issue on security and privacy for smart cities
}

\author{
Joseph K. Liu ${ }^{1}$ Kim-Kwang Raymond $\mathrm{Choo}^{2} \cdot$ Xinyi Huang ${ }^{3} \cdot$ Man Ho $\mathrm{Au}^{4}$
}

Published online: 1 August 2017

(C) Springer-Verlag London Ltd. 2017

\section{Erratum to: Pers Ubiquit Comput}

DOI 10.1007/s00779-017-1043-z

The name of Raymond Choo should be changed to Kim-Kwang Raymond Choo. The original version was corrected.

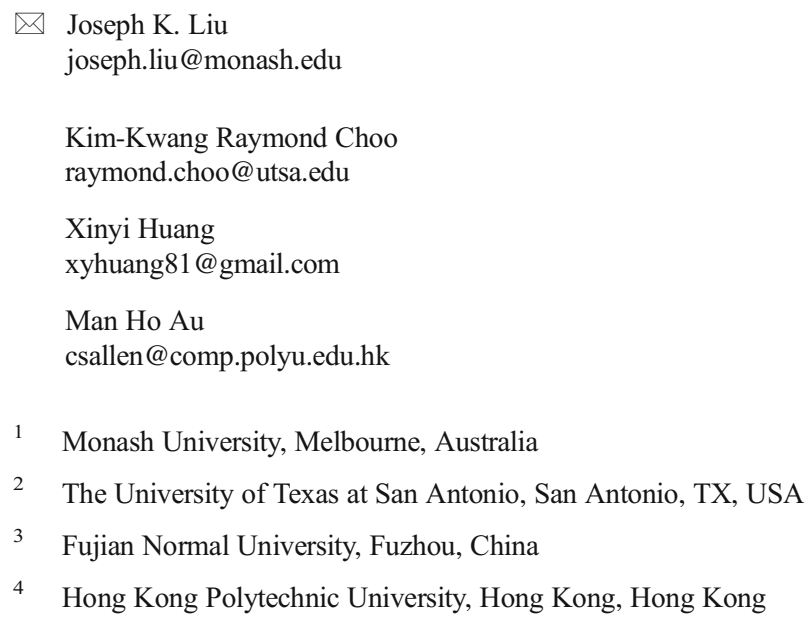

4 Hong Kong Polytechnic University, Hong Kong, Hong Kong 